\title{
Analysis of Essential Meteorological Elements Surrounding Typhoon Sinlaku by Unmanned Aerial Vehicle
}

\author{
Yang $\mathrm{Li}^{*}$, Shuqing Ma, Zhaobin Sun \\ Meteorological Observation Centre, CMA, Beijing, China \\ Email: "liyang@cma.gov.cn
}

Received 19 October 2015; accepted 5 January 2016; published 8 January 2016

Copyright (C) 2016 by authors and Scientific Research Publishing Inc.

This work is licensed under the Creative Commons Attribution International License (CC BY). http://creativecommons.org/licenses/by/4.0/

(c) (i) Open Access

\begin{abstract}
In this paper, a successful flight with an unmanned aerial vehicle (UAV) surrounded Typhoon Sinlaku on 15 Sept., 2008 and the preliminary analysis of all the collected data during the observation period has been presented. It is the first time to adopt surrounding method to observe typhoon in mainland of China. During the $3 \mathrm{~h}$ field campaign, the flight altitude is about $500 \mathrm{~m}$ to observe the essential meteorological elements in boundary layer of typhoon. The average temperature is $22.57^{\circ} \mathrm{C}$ and ranged from $21.50^{\circ} \mathrm{C}$ to $25.80^{\circ} \mathrm{C}$, while about the relative humidity, the maximum is $100 \%$, the minimum is $80.60 \%$ and the average is $97.98 \%$. As for the wind, the average wind speed is 19.68 $\mathrm{m} / \mathrm{s}$ and the maximum is $30.03 \mathrm{~m} / \mathrm{s}$. The typhoon center is a warm structure, the closer to the center, the higher the temperature is and the lower the wind speed is. In conclusion, the mini-UAV has the capability to observe the boundary layer of typhoon.
\end{abstract}

\section{Keywords}

Unmanned Aerial Vehicle (UAV), Typhoon, Observation, Meteorological Elements

\section{Introduction}

From 1997, National Hurricane Center had used jet engine to carry out sounding observation in the high troposphere and made use of GPS location system, which significantly improved the accuracy of horizontal wind field and timeliness and accuracy of typhoon forecasting [1]-[3]. The United States has utilized unmanned aerial vehicle with GPS sounder to research the hurricane which maybe influenced the United States and the Caribbean, and can lower the error to $10 \%-30 \%$ in the next $24-72 \mathrm{~h}$ typhoon route forecast [4], and the characteristics al-

"Corresponding author.

How to cite this paper: Li, Y., Ma, S.Q. and Sun, Z.B. (2016) Analysis of Essential Meteorological Elements Surrounding Typhoon Sinlaku by Unmanned Aerial Vehicle. Atmospheric and Climate Sciences, 6, 29-34.

http://dx.doi.org/10.4236/acs.2016.61003 
so suggested the intensity [5] and moving route [6]. In the early of 1990s, some scientists in Australian Bureau of Meteorology had put forward aerosonde, and wished to realize the tropical cyclone reconnaissance. In Nov. 1995, MCTEX experiment had been carried out in the Northern Australia by using aerosonde and several flying tests had also been conducted in Oregon and Western Australia [7]. Some research had also been done in Japan. Moteki et al. (2007) [8] had showed some results of reconnaissance in the tropical western Pacific region including wind, temperature, relative humidity and pressure. The results suggested that because of sounding data assimilated into the model, the improved wind error is $1-3 \mathrm{~m} / \mathrm{s}$ in the tropical Western Pacific region. A technical group called the Taiwan Aerosonde Team (TAT) has committed to research on typhoon reconnaissance [9]. In 2005, the TAT flew into the inner region of Typhoon Longwang and performed continuous measurements for about $10 \mathrm{~h}$. This flight provides the environmental information in Longwang along a $3000 \mathrm{~m}$ constant height ( 700 $\mathrm{hPa}$ ) path and a vertical sounding inside the eye. The derived surface pressure in the eye wall is close to the estimates made by the local weather agencies [10].

On the basis of studying the experience on typhoon observation in the international, Meteorological Observation Centre (MOC), China Meteorological Administration had carried out the first field campaign to observe Typhoon Kalmaegi by UAV in mainland of China on Jul. 18, 2008 [11]. This observation was successful that all data had been achieved during the observation and the UAV returned safely. Following that, MOC had adopted surrounding way to observe Typhoon Sinlaku (NO. 0813) and the essential meteorological elements had been obtained during the observation. The objective of this study is to obtain more observational data, thus to improve the accuracy of horizontal wind field and accuracy of typhoon forecasting and also do contribution to improve typhoon numerical forecasting model.

\section{Observation Test}

\subsection{Unmanned Aerial Vehicle (UAV)}

The instrument in this paper is meteorological unmanned aerial vehicle which was offered by Beijing Donghengyu Technology Development Center. The basic index of UAV is in Table 1.

\subsection{Flight Track}

According to the typhoon forecast from National Meteorological Center (NMC), CMA, Sinlaku maybe land at Ruian city in Zhejiang province. Therefore, Ruian city had been selected as the take-off and landing site. On the basis of the satellite image at 14:00 PM on 15 Sept. 2008 issued by National Satellite Meteorological Centre (NSMC), CMA, the flight track had been designed to surround Sinlaku. It is the first to adopt this method in mainland of China. The UAV took off at $14: 33$ at Ruian city $\left(120.69^{\circ} \mathrm{E}, 27.76^{\circ} \mathrm{N}\right)$ and the altitude is designed as $500 \mathrm{~m}$. After $3 \mathrm{~h}$ flight, the communication disrupted and the end longitude and latitude is $123.20^{\circ} \mathrm{E}$ and $26.11^{\circ} \mathrm{N}$, respectively. The flight track is show in Figure 1.

\begin{tabular}{|c|c|}
\hline Wing span & $2.90 \mathrm{~m}$ \\
\hline Length & $1.75 \mathrm{~m}$ \\
\hline Height & $0.71 \mathrm{~m}$ \\
\hline Weight & $12 \mathrm{~kg}$ \\
\hline Speed & $95 \mathrm{~km} / \mathrm{h}$ \\
\hline Navigation & GPS \\
\hline Altitude & $5000 \mathrm{~m}$ \\
\hline Endurance & $>7 \mathrm{~h}$ \\
\hline Operation & $\begin{array}{l}\text { Manual mode during takeoff and landing, and remote mode for out } \\
\text { of vision under autopilot and GPS navigation of flight computer }\end{array}$ \\
\hline $\begin{array}{l}\text { Variables } \\
\text { recorded }\end{array}$ & $\begin{array}{l}\text { Pressure, air temperature, humidity, wind speed and direction, altitude, } \\
\text { latitude/longitude, flight status, air speed, engine temperature }\end{array}$ \\
\hline
\end{tabular}




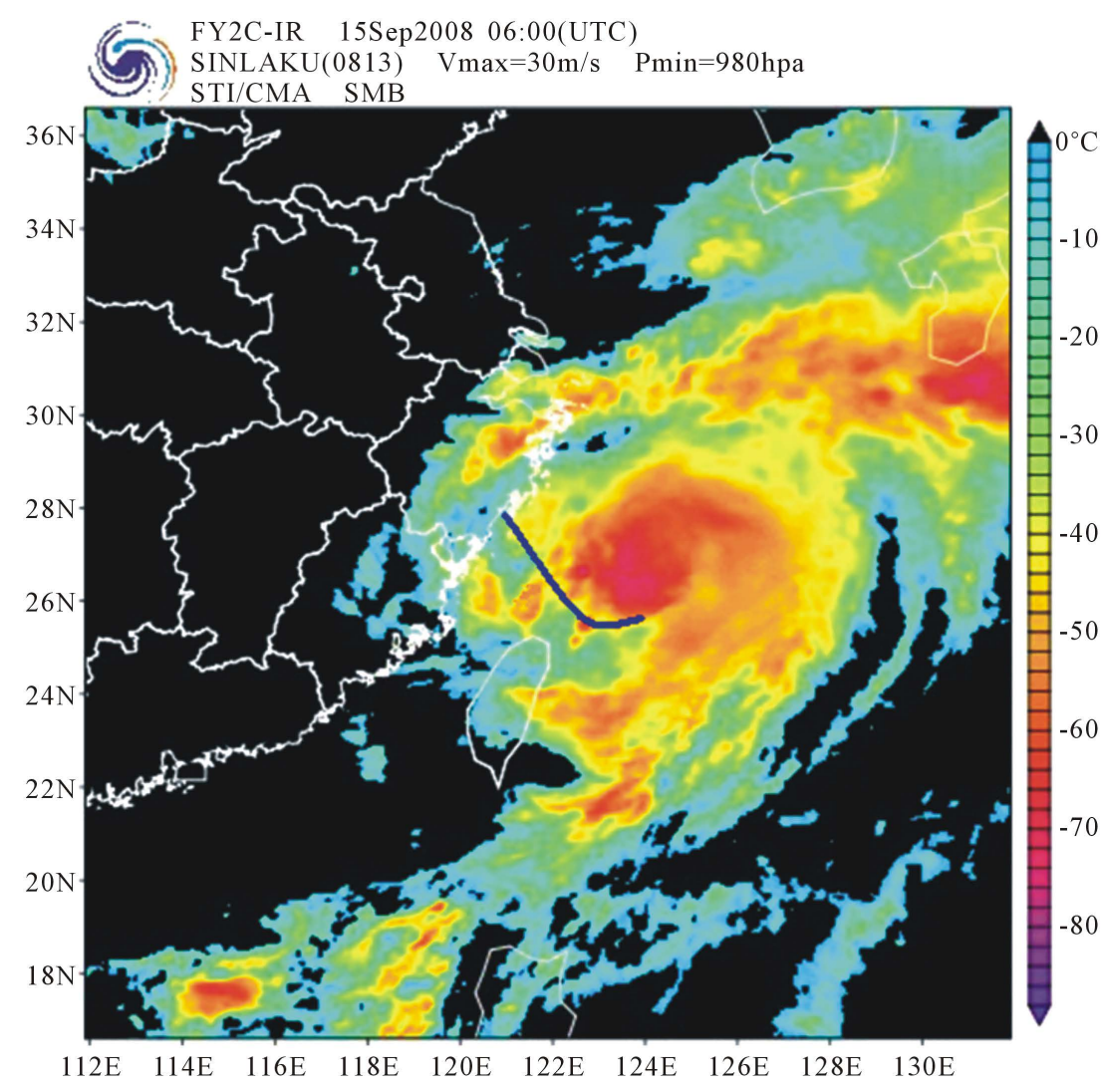

Figure 1. UAV’s flight track to observe Typhoon Sinlaku on 15 Sept. 2008 (the blue line stands for flight track).

From Figure 1 one can see that the UAV followed the airflow and entered the typhoon internal to carry out observation. The nearest distance to the typhoon center is about $100 \mathrm{~km}$.

\subsection{Observation Data}

The UAV equipped with meteorological sensors to observe temperature, pressure, relativity humidity and wind, and the observation data transmitted to the ground receiver through Beidou navigation system. One set of data transmitted every 10 seconds. 1065 sets should be received theoretically, but 847 had been accepted in actually and the data acquisition rate was about $80 \%$.

\section{Data Analysis}

\subsection{Altitude and Pressure}

The flight altitude was designed as $500 \mathrm{~m}$ and the average value is $508.98 \pm 19.47 \mathrm{~m}$ during the flight. From Figure 2, it can been seen that when the UAV's altitude is about $500 \mathrm{~m}$ and the fluctuation is little, which suggests that the UAV can keep good state in the hard weather conditions such as typhoon. Read from the pressure curve, during the climbing process from ground to $500 \mathrm{~m}$, the average value is $987.97 \pm 12.3 \mathrm{hPa}$. When the flight altitude is $500 \mathrm{~m}$, the average value is $941.74 \pm 2.34 \mathrm{hPa}$. From Figure 2, one can see that the pressure and the altitude have showed consistent anti-relation and the correlation coefficient is -0.99 , which further suggested that the data observed by the mini-UAV is true and credible.

\subsection{Temperature and Relative Humidity}

Figure 3 shows the variability of temperature and relative humidity of Typhoon Sinlaku observed by UAV. In terms of temperature curve, during the climbing process from ground to $500 \mathrm{~m}$, the average value is $22.38^{\circ} \mathrm{C}$, 


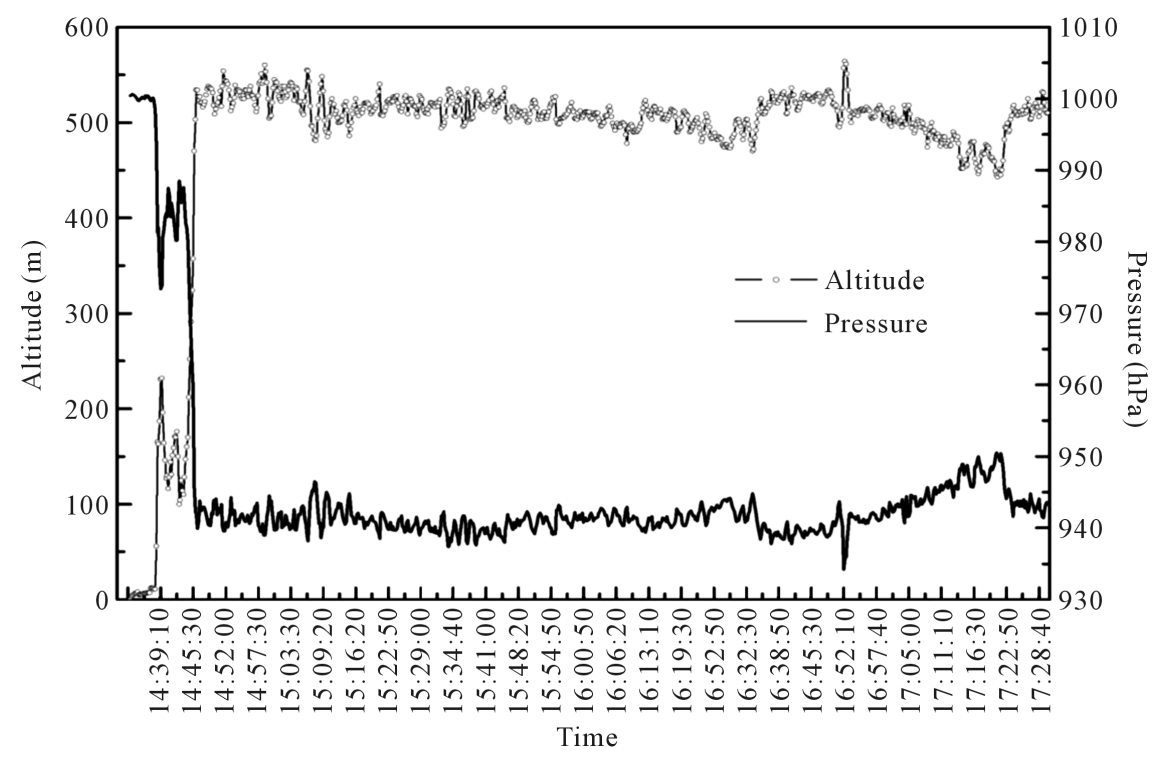

Figure 2. The variability of altitude and pressure of Typhoon Sinlaku observed by UAV.

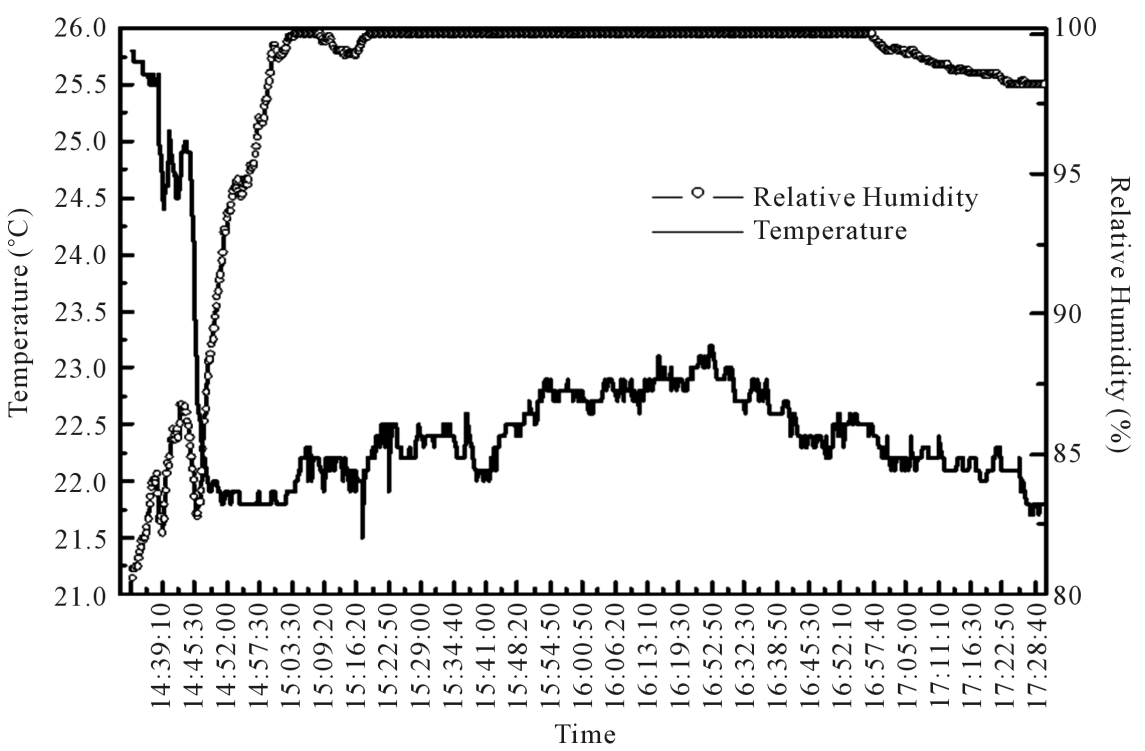

Figure 3. The variability of temperature and relative humidity of Typhoon Sinlaku observed by UAV.

the maximum is $23.20^{\circ} \mathrm{C}$ and the minimum is $21.50^{\circ} \mathrm{C}$. From this curve, when the flight altitude was relatively stable at $500 \mathrm{~m}$, temperature had a peak value at $16: 10$ which is $22.90^{\circ} \mathrm{C}$ and it was also the maximum during the $500 \mathrm{~m}$ process. According to the typhoon forecast information issued by NMC, it can be concluded that the UAV is in the closest distance from the typhoon center at 16:10 and the distance is about $100 \mathrm{~km}$. After that, Sinlaku moved gradually to the northeast. Because of the warm center structure of Sinlaku, high temperature occurred where is close to the center. It was observed that the temperature had reached the maximum in the stable altitude at 16:10, which indicated the UAV was close to the Sinlaku typhoon center. During the whole observation period, the average is $22.57^{\circ} \mathrm{C}$ and ranged from $21.50^{\circ} \mathrm{C}$ to $25.80^{\circ} \mathrm{C}$.

From the relatively humidity curve, one can see that during the climbing period the maximum value is $86.80 \%$, the minimum is $80.60 \%$ and the average is $83.87 \%$. At the beginning of climbing, there is no precipitation and the relative humidity is small. When the altitude is about $500 \mathrm{~m}$, the maximum is $100 \%$, the minimum is $82.80 \%$ and the average is $99.06 \%$, which suggests that $\mathrm{UAV}$ is within the precipitation cloud system, however, the UAV 


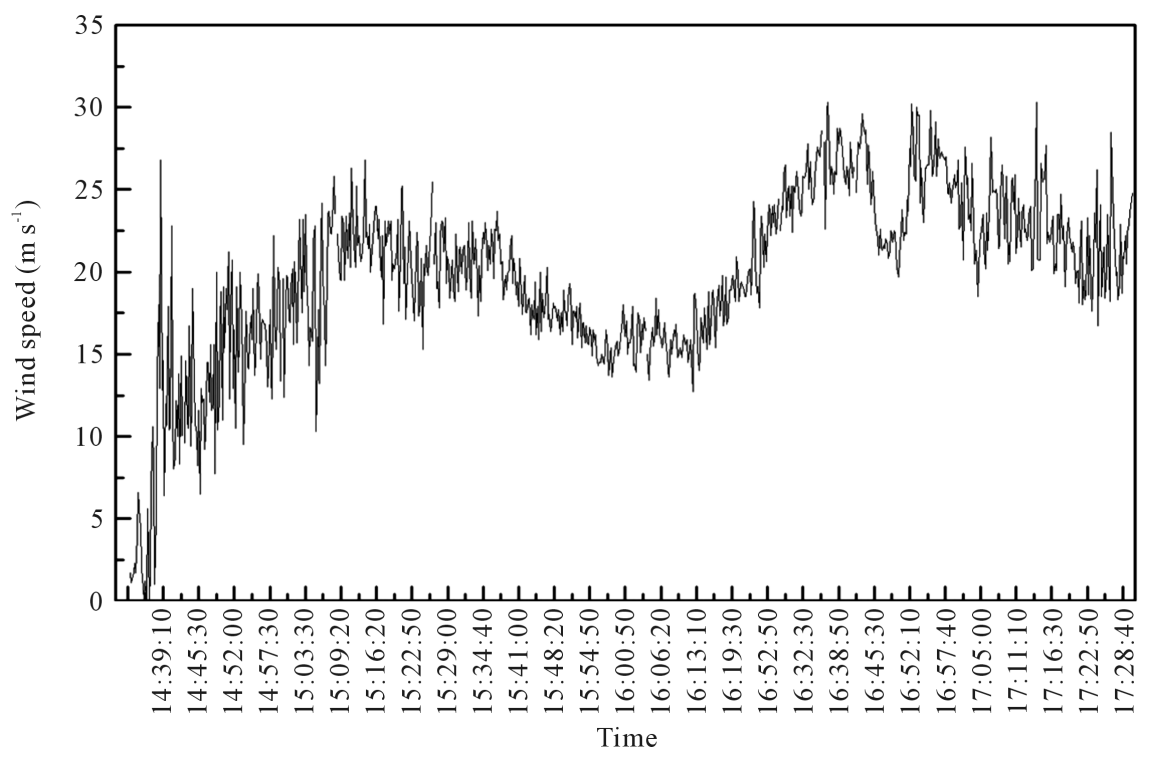

Figure 4. The variability of wind speed of Sinlaku observed by UAV.

can fly ordinarily in 3 hours, which suggests the waterproof performance of the mini-UAV is good. During the whole observation period, the maximum is $100 \%$, the minimum is $80.60 \%$ and the average is $97.98 \%$.

\subsection{Wind Speed}

During the climbing period, the maximum wind speed is $26.80 \mathrm{~m} / \mathrm{s}$ and the average is $8.87 \mathrm{~m} / \mathrm{s}$. When the altitude is about $500 \mathrm{~m}$, the maximum is $30.03 \mathrm{~m} / \mathrm{s}$, the minimum is $7.70 \mathrm{~m} / \mathrm{s}$ and the average is $20.50 \mathrm{~m} / \mathrm{s}$. Just as it mentioned early, it is at 16:10 that the UAV is in the closest distance from the typhoon center, from Figure 4 it can be seen that at that time the wind speed has the lowest value during the $500 \mathrm{~m}$ period, which is $12.7 \mathrm{~m} / \mathrm{s}$.

From the variability of wind speed, the standard deviation is small, furthermore, the flight state of UAV is relatively stable, which suggests it is feasible to observe typhoon by using UAV. The average value during the whole observation period is $19.68 \mathrm{~m} / \mathrm{s}$.

\section{Conclusions}

In this study, it was the first time to use the UAV equipped with meteorological sensors to observe temperature, pressure, relativity humidity and wind of Typhoon Sinlaku in China mainland. The following conclusions are found:

1) During this field campaign, the average meteorological elements are that temperature is $22.57^{\circ} \mathrm{C}$, relative humidity is $97.98 \%$, wind speed is $19.68 \mathrm{~m} / \mathrm{s}$ and pressure is $945.02 \mathrm{hPa}$;

2) The typhoon center has a warm structure, the closer to the centre, the higher the temperature is;

3) The UAV has the capability to observe the boundary layer of typhoon and can obtain the observation data during the flight mission.

\section{Acknowledgements}

This research work has been supported by Typhoon Special Funds of China Meteorological Administration and the Project (41475124) supported by NSFC. The authors thank the Beijing Donghengyu Technology Development Center to offer the UAV and Zhejiang Meteorological Bureau to help about the air traffic permission.

\section{References}

[1] Franklin, J.L., Black, M. and Valde, K. (2003) GPS Dropwindsonde Wind Profiles in Hurricanes and Their Operational Implications. Weather and Forecasting, 18, 32-44.

http://dx.doi.org/10.1175/1520-0434(2003)018<0032:GDWPIH>2.0.CO;2 
[2] Rogers, R., et al. (2006) The Intensity Forecasting Experiment: A NOAA Multiyear Field Program for Improving Tropicalcyclone Intensity Forecasts. Bulletin of the American Meteorological Society, 87, 1523-1537.

http://dx.doi.org/10.1175/BAMS-87-11-1523

[3] http://www.noaanews.noaa.gov

[4] Holland, G.J. (2002) Tropical cyclone Reconnaissanceusing Aerosonde UAV. World Meteorological Organization Bulletin, 51, 235-246.

[5] May, P.T. and Holland, G.J. (1999) The Role of Potential Vorticity Generationin Tropical Cyclone Rainbands. Journal of the Atmospheric Sciences, 56, 1224-1228.

[6] Powell, M.D. (1990) Boundary-Layer Structure and Dynamics in Outer Hurricanerainbands. Part II: Downdraft Modification and Mixedlayer Recovery. Monthly Weather Review, 118, 918-938. http://dx.doi.org/10.1175/1520-0493(1990)118<0918:BLSADI $>2.0$. CO;2

[7] http://www.aerosonde.com

[8] Qoosaku, M., Shirooka, R., Yoneyama, K., et al. (2007) The Impact of the Assimilation of Dropsonde Observations during PALAU2005 in ALERA. SOLA, 3, 97-100.

[9] Lin, P.H., Lee, C.-S., Yen, T.-C. and Lee, H.-C. (2003) Flying into Typhoon Haiyan with UAV Aerosonde. Preprints, 12th symposium on Meteorological Observations and Instrumentation, Long Beach, CA, 9-13 February 2003, 1-5.

[10] Lin, P. and Lee, C.-S. (2008) The Eyewall-Penetration Reconnaissance Observation of Typhoon Longwang (2005) with Unmanned Aerial Vehicle, Aerosonde. Journal of Atmospheric and Oceanic Technology, 25, 15-25. http://dx.doi.org/10.1175/2007JTECHA914.1

[11] Li, Y., Ma, S,Q., Wang, G.R. et al. (2009) Time-Space Characteristics of Meteorological Elements of Typhoon "Kalmaegi” by Using Unmanned Aerial Vehicle. Journal of Applied Meteorological Science, 20, 579-585. (In Chinese) 